\title{
Evaluating the impact of Hymenoscyphus fraxineus in Trentino (Alps, Northern Italy): first investigations
}

\author{
Stefano Giongo ${ }^{(1)}$, \\ Claudia Maria Oliveira Longa ${ }^{(2)}$, \\ Elisa Dal Maso ${ }^{(3)}$, \\ Lucio Montecchio ${ }^{(3)}$, \\ Giorgio Maresi ${ }^{(1)}$
}

\begin{abstract}
The spread of Hymenoscyphus fraxineus has been causing great concern regarding the survival of European ash (Fraxinus excelsior) throughout Europe since the 1990s. The disease was first recorded in Trentino (southern Alps, Italy) in 2012 and has spread throughout the mountain landscape, where ash trees are scattered in small and isolated stands in different valleys. The status of the disease was checked by monitoring the damage to natural regeneration and adult trees in 90 sites spread over the whole region. The survey confirmed the complete colonization by the pathogen of the whole investigated area, with high levels of damage to both young and adult ash trees. Regeneration (both seedlings and saplings) was observed to be affected by the fungus in 88 plots out of 90. Out of 4486 examined young European ashes, 2261 (50.4\%) were affected and $789(17.6 \%)$ were already dead. Ten of the 384 assayed flowering ashes (Fraxinus ornus) showed symptoms on branches and apical stems, similar to those observed for European ash. Isolation and molecular analysis proved the presence of the fungus on both symptomatic European and flowering ashes. The examined 386 adult trees showed different levels of damage, sometimes reaching more than $75 \%$ of the crown. Some individual trees (42) growing close to severely damaged trees appeared fully healthy, which suggests the possible existence of some resistant/tolerant individuals in the examined populations.
\end{abstract}

Keywords: Ash Dieback, Fraxinus excelsior, Fraxinus ornus, Natural Regeneration, Forest Management menoscyphus albidus (Roberge ex Gillet) W. Phillips, the common and autochthonous inhabitant of dead ash leaves (McKinney et al. 2012). The disease was first recorded in central Europe during the ' 90 , and it is currently spread over almost all the natural range of European ash (Fraxinus excelsior L.), also causing damage to narrow-leaved ash (F. angustifolia L.). Moreover, the fungus has showed its damaging potential on flowering ash (F. ornus L.), which can be infected artificially if seedlings are exposed to high inoculum levels (Kirisits \& Schwanda 2015). The colonization of the whole of Europe is almost complete, and the recent appearance of the disease on the Apen-
(1) Fondazione Edmund Mach, Centre for Technology Transfer, v. E. Mach 1, 38010 San Michele all'Adige, TN (Italy); (2) Fondazione Edmund Mach, Research and Innovation Centre, Department of Sustainable Agroecosystems and Bioresources, San Michele all'Adige, TN (Italy); (3) University of Padova, Department of Land, Environment, Agriculture and Forestry, v.le dell'Università 16, 35020 Legnaro, PD (Italy)

@ Giorgio Maresi (giorgio.maresi@fmach.it)

Received: May 08, 2017 - Accepted: Sep 20, 2017

Citation: Giongo S, Oliveira Longa CM, Dal Maso E, Montecchio L, Maresi G (2017). Evaluating the impact of Hymenoscyphus fraxineus in Trentino (Alps, Northern Italy): first investigations. iForest 10: 871-878. - doi: 10.3832/ifor2486-010 [online 2017-11-06] nines ridge (Luchi et al. 2016) also enables the possibility of severe damage to the Mediterranean area (Ghelardini et al. 2017). The pathogen can attack different tissues and tree organs; infection initially causes necroses in leaves, leading to the formation of necroses in rachises and petioles, from where the fungus colonizes shoots, twigs or the main stem, causing dieback of the crown, bark lesions (cankers) and sapwood discolouration (Kräutler \& Kirisits 2012). Ash trees of any age can be affected in all growth conditions, natural forests, plantations and nurseries (Schumacher et al. 2010, Kräutler \& Kirisits 2012, Gross et al. 2014).

The spread of infection is due to windborne ascospores released by apothecia growing on leaf rachises of the previous years. Because of the continuous production of ascospores in all vegetative seasons, the symptoms are mainly due to multiple and repeated infections (Hobson et al. 2016).

The concern about the ecological impact of this invasion is confirmed by several investigations carried out throughout Europe (Enderle et al. 2013, Havrdová et al. 2016, Hobson et al. 2016, Queloz 2016). Recently, the recovering of surviving plants in affected areas open up new possibilities for characterization and breeding of hyposensitive trees (Kjaer et al. 2011, Havrdová et al. 2016, Enderle et al. 2017a). 
In Italy, the disease was reported in 2009 on the boundary with Slovenia in the eastern part of the Alps (Ogris et al. 2010), and in the following years, it spread quickly towards the west, on the southern slope of the Alps. The colonization rate in these mountain areas was estimated to be 50-60 $\mathrm{km}$ per year (Luchi et al. 2012). In Trentino, the first record of the symptoms occurred in 2012 in the eastern part of the Province (Frigimelica \& Maresi 2012). Here, F. excelsior exists in, or dominates, ravine ashsycamore forests (CORINE biotopes 41.41), although the Trentino forests are mainly dominated by conifers (Picea abies Karst. and Larix decidua Mill). These ash stands cover small surfaces in the humid and fresh sites at the bottom of the valleys, playing an important role in biodiversity despite their size.

European ash is also one of the main species involved in the natural recolonization of abandoned pastures and meadows in endalpic valleys (Sitzia 2009). Its ability to colonize is also evident in several consolidated coniferous stands (Wolynski 2005), where it can spread alone or with other hardwood species under cover. These new formation stands could play a potential economic role for the commercial value of the wood (Wolynski 2005). Here, the presence of trees occurs mainly in small stands of new formation or along edges, or single or groups of trees are isolated in the traditional landscape and regenerate under other species cover. Few mature stands dominated by ash are also present, thus resulting in a highly fragmented distribution.

In 2014, damage due to the disease was reported in all the valleys, confirming the fast spread probably favored by particular weather conditions (high rates of precipitation during the vegetative seasons of both 2013 and 2014 - Maresi 2014). This rapid colonization, even in this context of very fragmented stands, enhances the risk of a possible heavy ecological impact of the disease.
Although European ash plays a minor role in the silvicultural management of Trentino forests, it seems important to evaluate and quantify this possible impact. To this purpose, a survey was carried out to estimate the damage to the natural regeneration of ash. Moreover, adult trees were assessed and mapped, aiming to establish permanent points of monitoring the disease progression in the future.

\section{Materials and methods}

\section{Field investigations}

Field investigations were carried out over the whole province of Trento (northern Italy). A distribution map of $F$. excelsior stands was kindly provided by the Forest and Fauna Service of Autonomous Province of Trento. In each forest administrative district, surveys were carried out aiming to identify the most representative areas of natural regeneration and groups of adult trees, and to cover the whole area reported to be colonized by the tree species. Considering the high irregular distribution of ash stands, each plot was chosen at a distance of approximately $3 \mathrm{~km}$ from each other, resulting in total of 90 surveyed sites (Fig. 1). The evaluation of the presence and damage of the disease was carried out during the 2016 vegetative season, starting at the end of July and finishing at the beginning of October.

\section{Regeneration evaluation and the} presence of $\mathrm{H}$. fraxineus fruiting bodies The selected plots were geo-located with a high-precision GPS (Garmin Montana 650T). At each identified point, a survey was carried out using a transect $10 \mathrm{~m}$ long and $4 \mathrm{~m}$ wide. For each transect, the following general characteristics were recorded: (i) altitude; (ii) aspect; (iii) stand type (wood edge, open field regeneration, hedgerow, under cover regeneration).

The whole area of the transect was accurately surveyed, mapping each seedling, sapling or young ash tree (F. excelsior and F. ornus). For each individual ash, height $(<20 \mathrm{~cm}, 21-100 \mathrm{~cm}, 101-200 \mathrm{~cm},>200 \mathrm{~cm})$, diameter at the collar $(<2 \mathrm{~cm}, 2-4 \mathrm{~cm},>4$ $\mathrm{cm}$ ) and type of tissue (lignified or herbaceous) were recorded. For the evaluation of the level of damage, the following classes were adopted:

(0) asymptomatic;

(1) initial attacks on leaves (dead leaves) and affected minor branches, up to a maximum of 5 ;

(2) more than 5 symptomatic or dead branches and/or the presence of stem cankers;

(3) apical shoot dead;

(4) dead plant.

Additional data such as the number of cankers on stems and branches, the length of the dead apical shoot and the presence of basal resprouting was also recorded.

Moreover, the presence of $\mathrm{H}$. fraxineus fruiting bodies in the litter of each transect was assessed.

\section{Adult tree evaluation}

Wherever possible, groups of $F$. excelsior adult trees were randomly selected near $(50-100 \mathrm{~m})$ the regeneration plots. A maximum of six trees per site, if present, were mapped with GPS and surveyed. Dendrological characteristics (height and diameter at breast height) were recorded together with social position (dominant, codominant, dominated and isolated). The loss of crown due to $\mathrm{H}$. fraxineus was evaluated according to five classes (Müller \& Stierlin 1990, modified):

(o) asymptomatic;

(1) defoliation or desiccation up to $1 / 5$ of the whole crown;

(2) defoliation or desiccation from $1 / 5$ to $1 / 2$ of the whole crown;

(3) defoliation or desiccation from $1 / 2$ to $3 / 4$ of the whole crown;

(4) defoliation or desiccation over $3 / 4$ of the whole crown.

Moreover, the presence of other fungal attacks on stems or necroses on the collars were assessed.

\section{Fungal isolation and molecular analysis}

The samples of symptomatic stems or branches were randomly collected in several selected plots to confirm the presence of the fungus: cankers, affected main stems or branches were picked up and transferred to the lab in plastic bags. Eight wood samples of $F$. excelsior and seven of $F$. ornus were processed. Following the methods of Stanosz et al. (2001), the external surface of each sample was disinfested for $10 \mathrm{~s}$ in $95 \%$ ethanol followed by $4 \mathrm{~min}$ in $2 \% \mathrm{NaOCl}$ solution with 2 drops of Tween 80 per litre. After cutting in aseptic conditions, fragments were excised from discoloured wood. Ten fragments per sample were randomly selected and placed on potato dextrose agar (PDA, Oxoid) in Petri dishes and incubated at $25^{\circ} \mathrm{C}$ for ten days in the dark. Other pieces of the same wood 
samples were placed into sterile Eppendorf tubes for DNA tests. The same procedure was adopted for seemingly symptomatic samples collected from $F$. ornus seedling or saplings. After 15 days, colonies showing the characteristics reported for those of $H$. fraxineus were transferred to fresh PDA plates. These colonies were checked after a week to confirm the morphological identification.

The same samples collected for isolation were also assayed for DNA extraction. Plant material was frozen in liquid nitrogen for 5 min, crushed in a Retsch Mixer Mill ${ }^{\oplus}$ MM200 (Qiagen, the Netherlands) for 2 min at a frequency of $25 \mathrm{~Hz}$ and then stored at $-20{ }^{\circ} \mathrm{C}$ until use. DNA was extracted using a DNeasy Plant Mini kit ${ }^{\oplus}$ (Qiagen, Hilden, Germany) according to the manufacturer's instructions. Species-specific primers designed by Johansson et al. (2010) were used to detect infections directly from plant tissue. The PCR mixture comprised $12.5 \mu \mathrm{l}$ of GoTaq Green Master Mix (Promega), $10.5 \mu$ l of water supplied with the GoTaq ${ }^{\oplus}$, each primer at $0.2 \mathrm{mM}$ (Sigma-Aldrich) and $1 \mu$ of DNA. A Biometra T1 Thermocycler (Whatman Biometra, Gottingen, Germany) was used for PCR with the following protocol: $5 \mathrm{~min}$ at $95^{\circ} \mathrm{C}$; 35 cycles of denaturation at $95^{\circ} \mathrm{C}$ for $30 \mathrm{~s}$, annealing at $62^{\circ} \mathrm{C}$ for $30 \mathrm{~s}$ and extension at $72{ }^{\circ} \mathrm{C}$ for $1 \mathrm{~min}$; and a final extension step at $72{ }^{\circ} \mathrm{C}$ for $10 \mathrm{~min}$. PCR fragments were analysed using $1 \%$ agarose gel electrophoresis in 1× Tris-boric acid-EDTA buffer (TBE), stained with SYBR Safe ${ }^{\circledast}$ (Life Technologies, Milan, Italy) and visualized under UV light. As a size standard, the GeneRuler DNA ladder mix $^{\otimes}$ (Thermo Scientific, USA) was used. Each DNA sample was assayed in duplicate. Negative controls (sterile water) and a positive control (DNA extracted from ascomata of $\mathrm{H}$. fraxineus, accession number KY593990 - Fig. S1 in Supplementary material) were included in all PCR runs.

\section{Statistical analysis}

To analyse the damage level in the regeneration, the level of damage index (LDI) was calculated for each plot as (eqn. 1):

$$
L D I=\frac{\sum_{i=1}^{5} n_{i} \cdot(i+1)}{5 \cdot N}
$$

where $n$ is the number of $F$. excelsior individuals in each damage level $i$ and $N$ is the total number of individuals in the plot. In order to evaluate the degree of spatial autocorrelation between neighbouring plots, Moran's I test was used in ArcGIS Desktop 10.2 software (ESRI 2011) using the coordinates of each plot and its respective level of damage index (Al-Kindi et al. 2017, Nkeng et al. 2017). The collinearity among characteristics of a single seedling (type of tissue, height, diameter) and of the site (altitude, aspect, stand treatment) was first checked based on the Pearson correlation $(a=0.01)$ using $R$ cran ( $R$ Core Team -
Tab. 1 - Distribution and percentages of the sampled ash regeneration (seedlings and saplings) in the different damage classes.

\begin{tabular}{lcccccc}
\hline \multirow{2}{*}{ Species } & \multicolumn{5}{c}{ Damage classes } & $\begin{array}{c}\text { Total } \\
\text { Individuals }\end{array}$ \\
\cline { 2 - 6 } F. excelsior & $\mathbf{0}$ & $\mathbf{1}$ & $\mathbf{2}$ & $\mathbf{3}$ & $\mathbf{4}$ & (225 \\
& $(49.6 \%)$ & $(8.1 \%)$ & $(3.3 \%)$ & $(21.4 \%)$ & $(17.6 \%)$ & 4486 \\
F. ornus & 374 & 3 & 1 & 6 & 0 & 384 \\
Total & $(97.4 \%)$ & $(0.8 \%)$ & $(0.3 \%)$ & $(1.5 \%)$ & $(0 \%)$ & \\
\hline
\end{tabular}

http://www.r-project.org). Subsequently, the association between the level of damage index (transformed to continuous response variable by angular transformation) and predictors was tested using ANOVA. When the result from a dependent variable indicated significant differences $(p<0.05)$, these were tested with multiple comparison tests (Tukey's HSD test, $a=0.05, \mathrm{R}$ library agricolae).

The presence of fruiting bodies on the soil was analysed as a function of the main characteristics of the transect (altitude, aspect, stand treatment) and the date of discovery using a conditional inference tree in $\mathrm{R}$ cran (library party). Values of site altitude were grouped into 3 classes: $(1) \leq 800 \mathrm{~m}$ a.s.l.; (2) > 800 and $\leq 1000 \mathrm{~m}$; and (3)> $1000 \mathrm{~m}$. Aspect was reduced to 8 classes: north, northeast, east, southeast, south, southwest, west, northwest. The performance of the model was evaluated by means of the contingency table (also called confusion matrix).

As for regeneration, the level of damage index for adults was calculated, then spatial autocorrelation between neighbouring plots was tested using Moran's I test; additionally, the level of damage index was tested against tree (height, diameter, social position) and site characteristics (altitude, aspect, stand treatment) after checking the collinearity of predictors with ANOVA (percentage data were modified by angular transformation), followed by multiple comparison tests (Tukey's HSD, $a=$ 0.05 , library agricolae).

\section{Results}

\section{Regeneration assessment}

The regeneration of $F$. excelsior was affected by $\mathrm{H}$. fraxineus in all the forest districts and in all the investigated valleys. No damage was observed only in two plots out of 90, both located in Val di Sole (eastern part of Trentino) and both having only seedlings still in the herbaceous phase. In these areas, however, the disease symptoms (Fig. S2, Supplementary material) were detected on other trees close to the transect. In 5 plots, all the surveyed trees were affected by the disease; in 54 plots, the total number of affected individuals was more than $50 \%$. Regarding mortality, only 10 plots showed no dead individuals, while in 53 plots mortality was > $10 \%$. Among them, 20 plots had more than 20\% dead trees. Only in 4 plots the reported mortality was more than $50 \%$ of the assayed individuals. The highest level of mortality reached $74 \%$.

A total number of 4870 ash young trees were assessed during the survey (Tab. 1). Among them, 92.1\% were European ash, while $7.9 \%$ were flowering ash. Regeneration ranged from a minimum of 12 to a maximum of 202, with an average of 54 individuals per plot. The disease affected $50.4 \%$ of the young F. excelsior trees in the plots, while only $2.6 \%$ of the $F$. ornus plants showed some symptoms. For European ash trees, most of the symptomatic trees (21.4\%) showed heavy damage with the loss of the terminal shoot (class 3) and $17.6 \%$ were dead due to the attack of $H$. fraxineus with no sign of other pathogens. Only $1.5 \%$ of $F$. ornus were badly damaged (class 3) but no individual was dead. Necrotic spots on leaves were observed on another 518 subjects, 383 of $F$. excelsior and 135 of $F$. ornus, suggesting a possible (though not confirmed) infection of almost $20 \%$ of saplings in damage class 0.

Spatial autocorrelation analysis using Moran's I test on plot LDI values did not reveal any significant departure from random distribution $(p=0.538, z$-score $=0.617)$.

Height, diameter and type of tissue variables were highly correlated $(p<0.01)$. The analysis of variance showed no significant differences in LDI among different stand typology $(p=0.6)$ or different aspect $(p=$ 0.218 ), whereas significant differences in the level of damage index were observed for seedling height and diameter, type of tissue and altitude (Tukey's HSD test, $\mathrm{p}<$ 0.05).

The distribution of the surveyed European ashes in the height classes was as follows: $10.6 \%$ in class $1(<20 \mathrm{~cm}), 44.2 \%$ in class $2(21-100 \mathrm{~cm}), 27.7 \%$ in class 3 (101-200 $\mathrm{cm})$ and $17.5 \%$ in class $4(>200 \mathrm{~cm})$. Most of the trees in class 1 (94\%) were healthy, while single individuals showed heavy damage $(1 \%)$ or were dead (3\%). A significant increase (Tukey's HSD test, $\mathrm{p}<0.05$ ) in damaged trees was observed for class 2, where mortality reached $15 \%$ and heavy damage reached $12 \%$. In class 3 , mortality increased to $25 \%$ and heavy damage to $31 \%$, and these values were significantly different $(p<0.05)$ from those in the previous height classes. Similarly, for class 4 , the recorded mortality was $20 \%$, and the heavy damage was $42 \%$ (Fig. 2). 


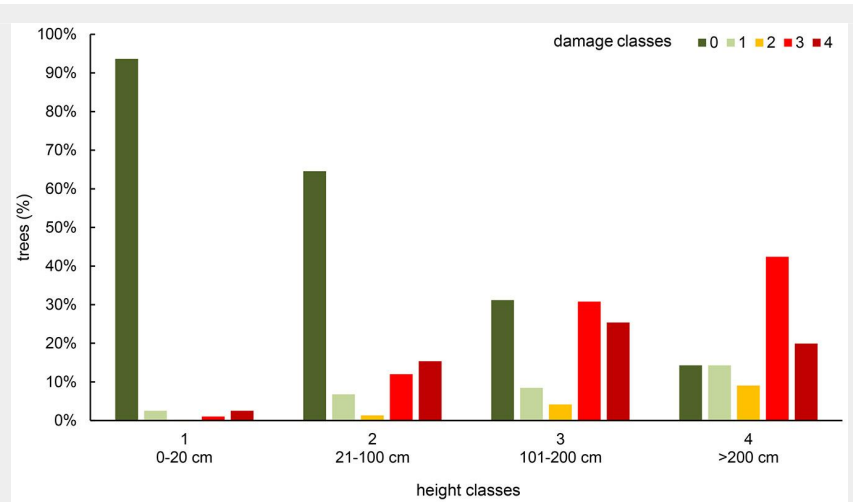

Fig. 2 - Distribution of young F. excelsior trees in class of damage, according to height classes.

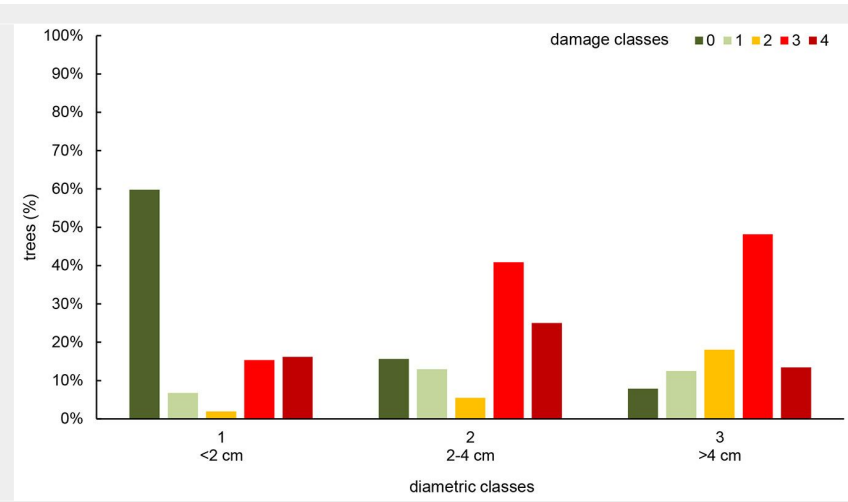

Fig. 3 - Distribution (in percentage) of young F. excelsior trees in class of damage, according to diametric classes.
Considering the distribution of diametric classes of $F$. excelsior regeneration, $77.8 \%$ young trees were recorded in the lower class $(<2 \mathrm{~cm})$, while $17.4 \%$ and $4.8 \%$ were recorded in the other two classes $(2-4 \mathrm{~cm}$ and $>4 \mathrm{~cm}$, respectively). Most individuals of the lower class appeared healthy (60\%). In the intermediate class, the number of healthy plants significantly decreased to $16 \%$, with a correspondent increase of the most affected ones to $41 \%$ (Tukey's HSD test, $\mathrm{p}<0.05) ; 25 \%$ of these trees were dead. The upper class showed only $8 \%$ of healthy trees, while $48 \%$ of subjects occurred in a damage class, and $13 \%$ were already dead (Fig. 3); these values were significantly differed from those observed in the first class (Tukey's HSD test, $p<0.05$ ).

Regarding the tissue status of $F$. excelsior seedlings and saplings, most of them were already lignified (86.7\%), while $13.4 \%$ were assessed as herbaceous. As shown in Fig. 4, most herbaceous seedlings were healthy, even if single plants appeared symptomatic or dead (Tukey's HSD test, $\mathrm{p}<0.05$ ).

Regarding the additional data on symptom expression, the highest number of young trees with basal resprouting fell within the third level of damage. Similarly, the highest numbers of necroses on stems and branches and the longest ones were detected in the same class of damage, with a maximum average number of necroses of 0.55 for seedlings taller than $200 \mathrm{~cm}$. With respect to the dead apical shoot, an average length of $134.71 \mathrm{~cm}$ was representative for damages in seedlings of the same height category.

As a further result of the ANOVA, altitude significantly affected the levels of damage of young seedlings (Fig. 5). In particular, the percentage of asymptomatic $F$. excelsior increased from $47 \%$ to $54 \%$ at altitudes ranging from $800-1000 \mathrm{~m}$ and higher than $1000 \mathrm{~m}$. Similarly, the percentage of ash trees in class 4 decreased from $21-23 \%$ to $11 \%$. The number of trees in the intermediate class ( 1 to 3 ) did not change by more of $3 \%$ among altitude classes.

Flowering ash proved to be less susceptible to dieback as compared with European ash. Only 10 individuals out of 384 showed symptomatic branches or stems (Fig. 6). In three plants, small branches were dead and discoloured. In one young tree, more than 5 branches were dead, and in the remaining 6 cases the apical shoot was dead from the terminal bud to the first internode. Discolouration was observed in internal tissues, but generally, it was limited to the wood in correspondence to the external necroses (Tab. 2). No dead foliage at- tached to dead branches was present, but necrotic spots were observed on the foliage of several subjects. Plants with dead branches or stems were found in 4 of the 10 plots where $F$. ornus was recorded. In these areas, infection on F. excelsior ranged from $54 \%$ to $100 \%$ of the trees, while the observed mortality ranged from $0 \%$ to $18 \%$.

The fruiting bodies of $\mathrm{H}$. fraxineus were frequently recorded in the investigated area. In particular, their presence was detected in 52 plots out of 90.

The developed conditional inference tree model showed a fairly good fitting of data, with an overall accuracy of $84.4 \%$, a specificity of $84.1 \%$ and a sensitivity of $84.6 \%$. Irrespective of the other included variables (altitude, aspect, stand treatment), the final model comprised only the date of the survey as predictor. In particular, the highest number of sites with the presence of fruiting bodies was recorded before the end of September (86.3\%), while in October, the detection of fruiting bodies was rarer (20.5\%).

\section{Adult tree evaluation}

Three hundred eighty-six trees were monitored to assess the disease impact on adult ash trees. Some 344 (89\%) were reported as infected even if they displayed

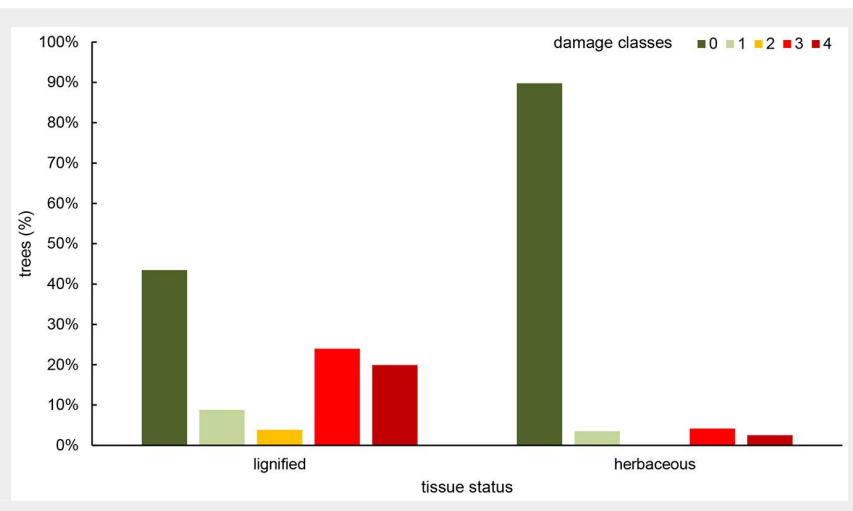

Fig. 4 - Distribution of young F. excelsior trees in class of damage, according to tissue status.

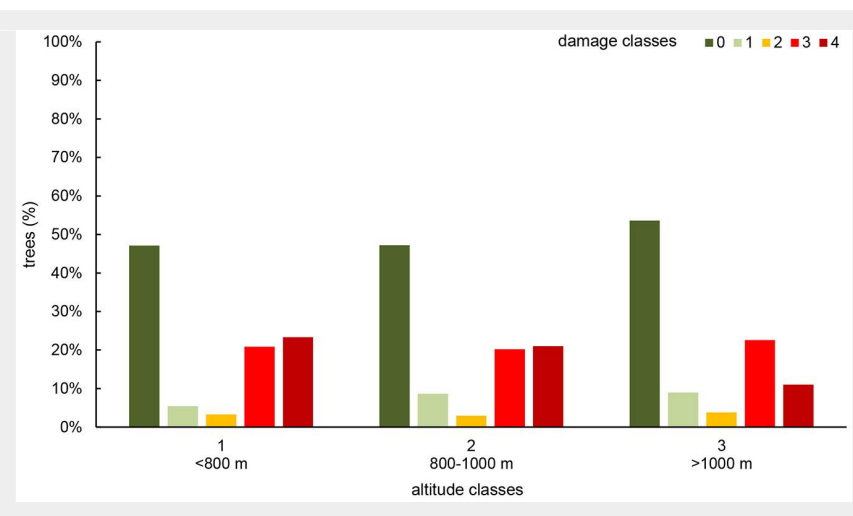

Fig. 5 - Distribution of young $F$. excelsior trees in class of damage, according to stand altitude ( $m$ a.s.l.). 


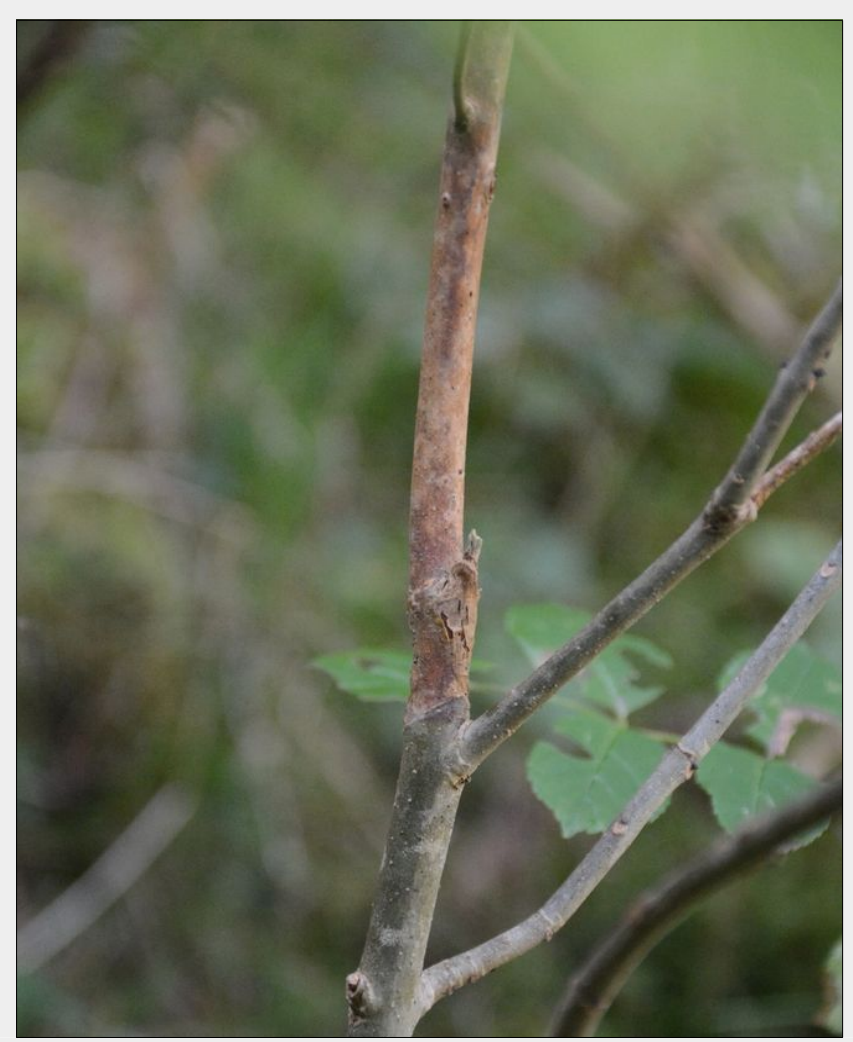

Fig. 6 - Colonization of F. ornus stem by $H$. fraxineus: presence of the fungus in wood tissues was confirmed by isolation and molecular analysis.

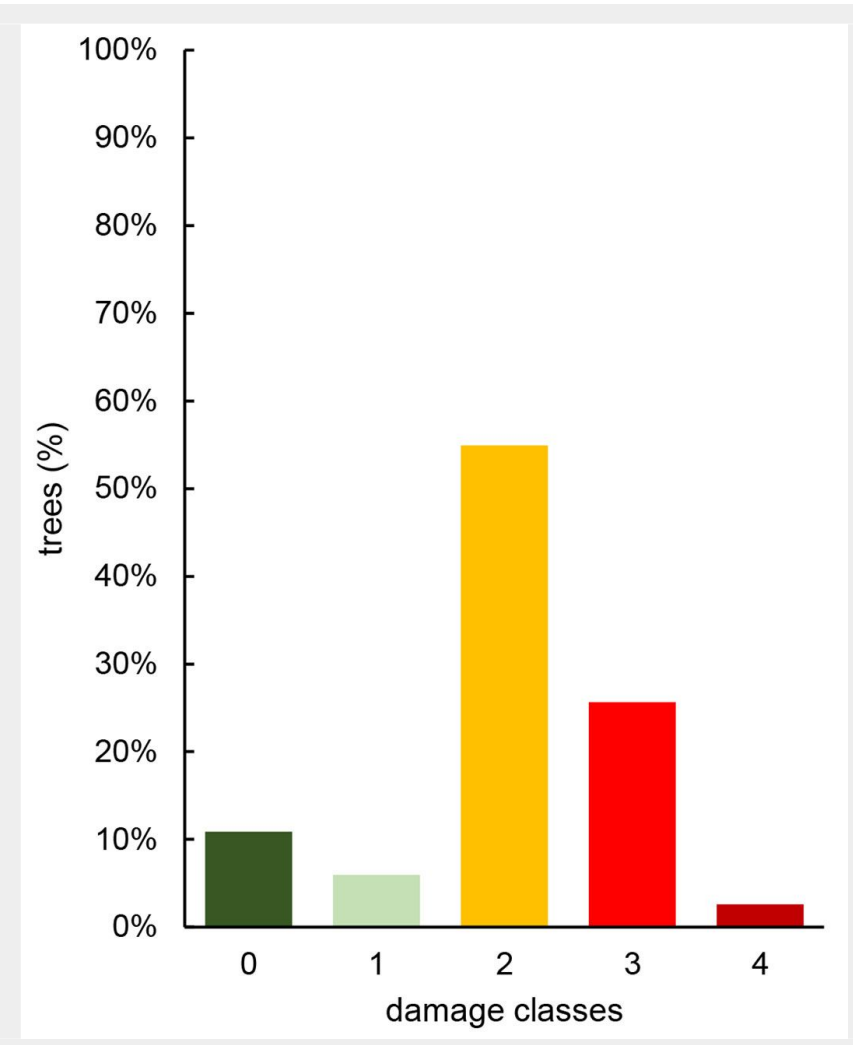

Fig. 7 - Distribution of the surveyed F. excelsior adult trees in the different classes of damage. different patterns of damage. Most of them (212, i.e., $55 \%$ ) belonged to class 2 , with 20 to $50 \%$ of the crown damaged; for 99 (25.5\%), the damage reached class 3 . As for the other 10 individuals (2.5\%), more than $75 \%$ of the crown was already damaged, but the trees were still alive. Initial attacks were present on 23 trees (6\%). No dead trees were observed. Forty-two trees (11\%) were recorded as completely free of symptoms and with complete foliage (Fig. 7).

Spatial autocorrelation analysis indicated the absence of any spatial correlation of affected stands in the region ( $p=0.928, z-$ score $=0.09$ ). Most of the trees were in class 2 of damage and both healthy trees and the most damaged ones were observed in each social, diametric and height classes (Tab. 3). The analysis of variance showed no significant differences in terms of height, diameter and social position of single trees or in terms of altitude, aspect and stand treatment used as predictors (Tab. 3).

Healthy trees were observed across all the valleys, even in those already infested in 2012 (Vanoi, Primiero and Valsugana). In some cases, healthy individuals were observed very close to severely affected trees (Fig. S3 in Supplementary material).

No fruiting bodies of other fungi were detected on the surveyed trees, including those severely affected by the disease. On these trees, no basal necroses or other symptoms of decline were observed.

Fungal isolation and molecular analysis Fungal colonies with morphological characters resembling those described for $H$. fraxineus were obtained from 6 samples out of 8 branches or apical shoots of F. excelsior. Positive isolation occurred in 3 of 7 infected samples of $F$. ornus (Tab. 2 ).
Molecular analysis using species-specific primers revealed the presence of $H$. fraxineus in seven wood samples of $F$. excelsior and in six samples of $F$. ornus assayed. DNA amplification allowed to identify the presence of the pathogen based on characteristic bands which were compared to those of the positive control of $H$. fraxineus.

The two above methods (culture media

Tab. 2 - Results of fungal isolations in culture media and molecular analysis carried out on affected samples of F. excelsior and F. ornus. (*): Sample collected near the plot.

\begin{tabular}{llcc}
\hline Site & Species & $\begin{array}{c}\text { Fungal } \\
\text { isolation }\end{array}$ & $\begin{array}{c}\text { Molecular } \\
\text { analysis }\end{array}$ \\
\hline Val dei Mocheni (Plot 75) & Fraxinus excelsior & + & + \\
Val Genova (Plot 83) & Fraxinus excelsior & + & + \\
Val Maso (Plot 73) & Fraxinus excelsior & + & + \\
Val Ambiez (Plot 63) & Fraxinus excelsior & + & + \\
Vanoi (Plot 65) & Fraxinus excelsior & + & + \\
Val di Sella (Plot 70) & Fraxinus excelsior & + & + \\
Val di Sella (Plot 72) & Fraxinus excelsior & - & + \\
Tione (Plot 72) & Fraxinus excelsior & + & + \\
Val Ambiez (Plot 72)* & Fraxinus ornus & + & + \\
Lavarone (Plot 86) & Fraxinus ornus & + & + \\
Val Maso (Plot 73) & Fraxinus ornus & - & + \\
Val di Sella (Plot 72) & Fraxinus ornus & - \\
Val di Fiemme (Plot 6) & Fraxinus ornus & - & + \\
Primiero (Plot 67) & Fraxinus ornus & + \\
Primiero (Plot 47) & Fraxinus ornus & + \\
\hline
\end{tabular}


Tab. 3 - Distribution of adult trees in the different damages classes for social (D: Dominant; CD: Codominant; d: dominated; F: free), diametric and height classes.

\begin{tabular}{llrrrrrr}
\hline \multirow{2}{*}{ Group } & \multirow{2}{*}{ Class } & \multicolumn{7}{c}{ Damage classes } & \multirow{2}{*}{ Total } \\
\cline { 2 - 6 } & & $\mathbf{0}$ & $\mathbf{1}$ & $\mathbf{2}$ & $\mathbf{3}$ & $\mathbf{4}$ & \\
\hline Social & $\mathrm{D}$ & 21 & 12 & 85 & 39 & 4 & 161 \\
position & $\mathrm{CD}$ & 16 & 2 & 70 & 26 & 3 & 117 \\
& $\mathrm{~d}$ & 1 & 1 & 18 & 15 & 1 & 36 \\
& $\mathrm{~F}$ & 4 & 8 & 39 & 19 & 2 & 72 \\
\hline DBH & $<25 \mathrm{~cm}$ & 17 & 14 & 119 & 63 & 7 & 220 \\
classes & $25-50 \mathrm{~cm}$ & 22 & 8 & 77 & 32 & 1 & 140 \\
& $50-75 \mathrm{~cm}$ & 2 & 1 & 13 & 4 & 1 & 21 \\
& $75-100 \mathrm{~cm}$ & 1 & 0 & 3 & 0 & 1 & 5 \\
Height & $<8 \mathrm{~m}$ & 1 & 4 & 17 & 8 & 1 & 31 \\
classes & $8-16 \mathrm{~m}$ & 24 & 11 & 127 & 50 & 4 & 216 \\
& $16-24 \mathrm{~m}$ & 15 & 7 & 59 & 39 & 5 & 125 \\
& $24-32 \mathrm{~m}$ & 2 & 1 & 9 & 2 & 0 & 14 \\
\hline
\end{tabular}

and molecular analysis) showed different results in $F$. excelsior and in $F$. ornus samples. The molecular analysis was more effective for diagnosing the presence of the pathogen in the wood samples, as compared the culture media method.

\section{Discussion and conclusion}

This survey confirmed that ash dieback has already colonized all the valleys of Trentino. The complete colonization occurred in approximately 4 years, considering the first record of the symptoms (Frigimelica \& Maresi 2012). The colonization apparently was not hindered by ecological barriers due to the mountainous topography. It is noteworthy that no movement of plant material nor plantation of ash seedling occurred between the valleys. Moreover, ash trees and wood are not commercialized in this region. The rate of colonization corresponds to $50 \mathrm{~km}$ per year, as already suggested by Luchi et al. (2012) for Northeast Italy. Such efficient spread in Trentino was probably favored by the particular weather conditions that occurred in 2013 and 2014, with high temperatures and precipitation during the entire growing season that were favourable to the fungus (Maresi 2014). Moreover, local microclimatic conditions in the valley, where humidity values can be elevated during the growing season, can also enhance the production of fruiting bodies, thus contributing to the spread of the pathogen.

Our results showed a clear impact of the disease on European ash regeneration, with damage and mortality observed almost everywhere. Only the seedling and the current year's growth seemed less affected by the disease, due to the modalities and the time of infections. Moreover, considering the individuals that displayed some foliage damage, the infection rates could increase by $10 \%$. Remarkably, a high levels of damage was recorded to the established regeneration plots, in which almost all trees were infected. The loss of apical shoots was regularly observed, which could lead to alteration of polar transport of auxin and to marked modifications of wood biometric traits, progressively leading to tree death (Tulik et al. 2017). Moreover, the apex loss was always associated with other attacks on branches or with cankers on the stems, thus further reducing the chance of survival. Therefore, though natural regeneration still occurred in all the surveyed plots, its survival up to the adult stage seems severely compromised. As observed in other countries (Germany and Latvia) where the disease has been occurring for a longer period, natural regeneration of European ash trees occurs also under a severe disease pressure, with damages modulated by different environmental conditions, as reported by Enderle Both the cited works reported that the health status of ash trees worsen with increasing height and age, suggesting that in our context tree survival needs to be monitored for a longer period to assess the real impact of ash dieback. Consistently, our results strengthened the hypothesis of less symptom expression in the youngest seedlings.

Regarding the relationship between the level of infection and stand characteristics, we observed that the average level of damage was lower at higher altitudes $(>1000 \mathrm{~m}$ a.s.l.). Elevation is highly correlated with many environmental variables that also influence vegetation type (Pignatti 2011), and the presence of $\mathrm{H}$. fraxineus is conditioned by summer precipitation and air temperature (Dal Maso \& Montecchio 2014). Investigations are needed to evaluate a possible role of these environmental factors in affecting the spread of the pathogen in higher mountain areas.

The recovery of affected $F$. ornus trees in natural conditions confirmed the pathogenicity of $H$. fraxineus on this species, as previously reported by Kirisits \& Schwanda (2015) which proved the fungus' ability in colonizing flowering ash leaves. The colonization of leaves (but not stems) was conet al. (2017b) and Pušpure et al. (2017). firmed on seedlings of $F$. ornus grown in a severely affected $F$. excelsior area (Kirisits 2017). In our study, the pathogen was detected in dead and discoloured wood tissues, showing a symptomatology similar to that observed on F. excelsior. In the few observed cases, the fungus seemed confined to the first internode and was unable to spread throughout the wood. Similar observations have been reported in Friuli Venezia Giulia (north-eastern Italy), where affected $F$. ornus trees were observed in mixed stands with $F$. excelsior (Bernardinelli 2016, 2017). Therefore, flowering ash seems to be susceptible to the fungal infections with evident damage, at least when growing together with severely affected $F$. excelsior or in presence of high loads of ascospores (Kirisits 2017). The ability of $H$. fraxineus to spread and colonize pure and mixed stands of $F$. ornus needs deeper investigations, as this forest type cover more than 40,841 ha in Trentino and approximately 852,202 ha across Italy (Gasparini \& Tabacchi 2011), mainly along the Apennines. The possibility of a dangerous spread of the disease also in these kinds of woodlands could also potentially lead to new troubling scenarios in the Mediterranean mountain region (Ghelardini et al. 2017).

Several adult trees with severe damage were observed in this study, though no dead trees were observed during the survey or were reported by the Forest Trees Damage Monitoring (FTDM) survey carried out for the Trentino forests (Salvadori et al. 2013). However, the observed trees having the crown already desiccated could further decline in the next few years, as already reported in northern and central Europe (Pautasso et al. 2012). Furthermore, the observed damage has already a strong visual impact, which could be reduced by appropriate pruning or endotherapy (Dal Maso et al. 2014, Marciulyniene et al. 2017) wherever the affected trees assume any landscape, touristic or ornamental values.

The extent of ash decline observed in Trentino is similar to that observed throughout Europe, as reported in several recent papers (Queloz 2016, Hobson et al. 2016, Laivinš et al. 2016): damage is severe and increasing in both juvenile and adult trees. However, the presence of asymptomatic trees in the surveyed area seems to suggest the existence of resistance or tolerance to the disease (Queloz 2016, Landolt et al. 2016). These plants could constitute the genetic reservoir for implementing the conservation of the species. Nevertheless, much research is needed to confirm this observation and delineate proper management techniques to exploit this potential tolerance (Rigling et al. 2016, Enderle et al. 2017b, Skovsgaard et al. 2017). Apparently, seedlings in the investigated plots seem susceptible to dieback even where asymptomatic adult trees were observed. Moreover, the exclusive sexual reproduction of the pathogen could easily 
overcome restrictive genetic resistance if evolutionary processes favour fungal genotypes of higher virulence (Landolt et al. 2016).

The level of damage has drastically hindered the silvicultural perspectives of European ash in Trentino forests. Also, its potential economical role as the major colonizer of forest gaps or neo-formation stands, as suggested by Wolynski (2005), might be completely lost.

The impact of $H$. fraxineus in the Alpine region is substantial. In any case, constant monitoring of the disease is needed in order to evaluate any possible evolution of future scenarios.

\section{Acknowledgements}

We would like to thank Emanuel Endrizzi, Elisa Zadra, Maria Claudia Ferretti, Matteo Poda, Alex Dallago, Giorgio Cordin, Chiara Facchinelli for their technical assistance in the field. We also thank Felice Dorna and Massimo Miori (Forest and Fauna Service, PAT, Trento, Italy) and Maurizio Salvadori (Parco Paneveggio and Pale S. Martino, Trento, Italy) for their help in the localization of ash stands.

\section{References}

Al-Kindi KM, Kwan P, Andrew NR, Welch M (2017). Modelling spatiotemporal patterns of dubas bug infestations on date palms in northern Oman: a geographical information system case study. Crop Protection 93: 113-121. - doi: 10.1016/j.cropro.2016.11.033

Baral HO, Queloz V, Hosoya T (2014). Hymenoscyphus fraxineus, the correct scientific name for the fungus causing ash dieback in Europe. IMA Fungus 5: 79-80. - doi: 10.5598/imafungus. 2014.05.01.09

Bernardinelli I (2016). BAUSINVE 2015: Inventario fitopatologico forestale regionale Stato fitosanitario delle foreste del Friuli Venezia Giulia [Forest phytopatological inventory, Forest health status in Friuli Venezia Giulia]. Notiziario ERSA 1-2016, Udine, Italy, pp. 8. [in Italian]

Bernardinelli I (2017). BAUSINVE 2016: Inventario fitopatologico forestale regionale Stato fitosanitario delle foreste del Friuli Venezia Giulia [Forest phytopatological inventory, Forest health status in Friuli Venezia Giulia]. Notiziario ERSA 1-2017, Udine, Italy, pp. 8. [in Italian]

Dal Maso E, Montecchio L (2014). Risk of natural spread of Hymenoscyphus fraxineus with environmental niche modelling and ensemble forecasting technique. Forest Research 3: 131. - doi: 10.4172/2168-9776

Dal Maso E, Cocking J, Montecchio L (2014). Efficacy tests on commercial fungicides against ash dieback in vitro and by trunk injection. Urban Forestry and Urban Greening 13 (4): 697703. - doi: 10.1016/j.ufug.2014.07.005

Enderle R, Peters F, Nakou A, Metzler B (2013). Temporal development of ash dieback symptoms and spatial distribution of collar rots in provenance trial of Fraxinus excelsior. European Journal of Forest Research 132: 865-876. - doi: 10.1007/s10342-013-0717-y

Enderle R, Fussi B, Lenz HD, Langer G, Nagel R, Metzler B (2017a). Ash dieback in Germany: research on disease development, resistance and management options. In: "Dieback of European Ash (Fraxinus spp.): Consequences and Guidelines for Sustainable Management" (Vasaitis R, Enderle R eds). Swedish University of Agricultural Sciences, Uppsala, Sweden, pp. 89105. [online] URL: http://www.researchgate. net/publication/313401451

Enderle R, Busskamp J, Metzler B (2017b). Growth performance of dense natural regeneration of Fraxinus excelsior under attack of the ash dieback agent Hymenoscyphus fraxineus. Baltic Forestry 23 (1): 218-228. [online] URL: http://www.balticforestry.mi.lt/bf/PDF_Articles/ 2017-23[1]/BalticForestry2017.1_218-228.pdf

ESRI (2011). ArcGIS Desktop, release 10. Environmental Systems Research Institute, Redlands, CA, USA. [online] URL: http://www.esri.com/ software/arcgis

Frigimelica G, Maresi G (2012). II deperimento del frassino [Ash Dieback]. Terra Trentina 58 (4): 54. [in Italian]

Gasparini P, Tabacchi G (2011). L'Inventario Nazionale delle Foreste e dei serbatoi forestali di Carbonio INFC 2005. Secondo inventario forestale nazionale italiano. Metodi e risultati [Forest and carbon sink National inventory INFC 2005. Second Italian National Forest inventory]. MIPAAF, CFS, CRA, Edagricole-II Sole 24 ore, Bologna, Italy, pp. 653. [in Italian]

Ghelardini L, Migliorini D, Santini A, Pepori AL, Maresi G, Vai N, Montuschi C, Carrari E, Feducci M, Capretti P, Luchi N (2017). From the Alps to the Apennines: possible spread of ash dieback in Mediterranean areas. In: "Dieback of European Ash (Fraxinus spp.): Consequences and Guidelines for Sustainable Management" (Vasaitis R, Enderle R eds). Swedish University of Agricultural Sciences, Uppsala, Sweden, pp. 140-149.

Gross A, Holdenrieder O, Pautasso M, Queloz V, Sieber TN (2014). Hymenoscyphus pseudoalbidus, the causal agent of European ash dieback. Molecular Plant Pathology 15: 5-21. - doi: 10.1111/ mpp.12073

Havrdová L, Novotná K, Zahradník D, Buriánek V, Pešková V, Srutka P, Cerny K (2016). Differences in susceptibility to ash dieback in Czech provenances of Fraxinus excelsior. Forest Pathology 46: 281-288. - doi: 10.1111/efp.12265 Hobson PR, Ibisch PL, Parmee R (2016). A small plot study of Chalara infestation in a recently established natural stand of ash, UK. Arboricultural Journal 38 (3): 122-133. - doi: 10.1080/030 71375.2016.1194029

Johansson BK, Vasaitis R, Ihrmark K, Barklund P, Stenlid J (2010). Detection of Chalara fraxinea from tissue of Fraxinus excelsior using speciesspecific ITS primers. Forest Pathology 40: 111115. - doi: 10.1111/j.1439-0329.2009.00614.x

Kirisits T, Schwanda K (2015). First definite report of natural infection of Fraxinus ornus by Hymenoscyphus fraxineus. Forest Pathology 45 (5): 430-432. - doi: 10.1111/efp.12211

Kirisits T (2017). Further observations on the association of Hymenoscyphus fraxineus with Fraxinus ornus. Baltic Forestry 23 (1): 60-67. [online] URL: http://www.balticforestry.mi.lt/bf/ PDF_Articles/2017-23[1]/BalticForestry2017.1_06 0-067.pdf

Kjaer ED, McKinney LV, Nielsen LR, Hansen LN,
Hansen JK (2011). Adaptive potential of ash (Fraxinus excelsior) populations against the novel emerging pathogen Hymenoscyphus pseudoalbidus. Evolutionary Applications 5 (3): 219-228. - doi: 10.1111/j.1752-4571.2011.00222.x

Kowalski T (2006). Chalara fraxinea sp. nov. associated with dieback of ash (Fraxinus excelsior) in Poland. Forest Pathology 36: 264-270. - doi: 10.1111/j.1439-0329.2006.00453.x

Kräutler K, Kirisits T (2012). The ash dieback pathogen Hymenoscyphus pseudoalbidus is associated with leaf symptoms on ash species (Fraxinus spp.). Journal of Agricultural Extension and Rural Development 4: 261-265.

Laivinš M, Priede A, Pušpure I, Gerra-Inohosa L (2016). Changes of young ash stands area in Latvia and invasion of Hymenoscyphus fraxineus. Proceedings of the Latvian Academy of Sciences, Section B 70 (3): 124-130.

Landolt J, Gross A, Holdenrieder O, Pautasso M (2016). Ash dieback due to Hymenoscyphus fraxineus: what can be learnt from evolutionary ecology? Plant Pathology 65: 1056-1070. - doi: 10.1111/ppa.12539

Luchi N, Montecchio L, Santini A (2012). Situation with ash in Italy: stand characteristics, health condition, ongoing work and research needs. In: Interim Report from the Meeting "Chalara fraxinea, FRAXBACK" (Mainprize N, Hendry S, Weir J eds). Vilnius (Lithuania) 13-14 Nov 2012. Forestry Commission, Bristol, UK, pp. 25-26.

Luchi N, Ghelardini L, Santini A, Migliorini D, Capretti $P$ (2016). First record of ash dieback caused by Hymenoschyphus fraxineus on Fraxinus excelsior in the Apennines (Tuscany, Italy). Plant Disease 100 (2): 535. - doi: 10.1094/PDIS09-15-0975-PDN

Marciulyniene D, Davydenko K, Stenlid J, Cleary $M$ (2017). Can pruning help maintain vitality of ash trees affected by ash dieback in urban landscapes? Urban Forestry and Urban Greening 27: 69-75. - doi: 10.1016/j.ufug.2017.06.017

Maresi G (2014). Il deperimento del frassino maggiore nel Trentino: diffusione dei danni durante l'estate 2014 [European ash dieback in Trentino: damages spread during 2014 summer]. Dendronatura 35 (2): 62-70. [in Italian]

McKinney LV, Thomsen IM, Kjr ED, Bengtsson SBK, Nielsen LR (2012). Rapid invasion by an aggressive pathogenic fungus (Hymenoscyphus pseudoalbidus) replaces a native decomposer (Hymenoscyphus albidus): a case of local cryptic extinction? Fungal Ecology 5: 663-669. - doi: 10.1016/j.funeco.2012.05.004

Müller E, Stierlin HR (1990). Sanasilva - Le chiome degli alberi [Tree crowns]. Swiss Institute for Forest, Snow and Landscape Research, Birmensdorf, Switzerland, pp. 129. [in Italian]

Nkeng NM, Mousseni IBE, Nomo LB, Sache I, Cilas C (2017). Spatio-temporal dynamics on a plot scale of cocoa black pod rot caused by Phytophthora megakarya in Cameroon. European Journal of Plant Pathology 147: 579. - doi: 10.1007/s10658-016-1027-2

Ogris N, Hauptman T, Jurc D, Floreanci V, Marsich F, Montecchio L (2010). First report of Chalara fraxinea on common ash in Italy. Plant Disease 94 (1): 133. - doi: 10.1094/PDIS-94-1-0133A Pautasso M, Aas G, Queloz V, Holdenrieder O (2012). European ash (Fraxinus excelsior) dieback - A conservation biology challenge. Biolog- 
ical Conservation 158: 37-49. - doi: 10.1016/j.bio con.2012.08.026

Pignatti G (2011). Forest vegetation in view of some scenarios of climate change in Italy. Forest@ - Rivista di Selvicoltura ed Ecologia Forestale 8 (1): 1-12. [in Italian with English summary] - doi: 10.3832/eforo650-008

Pušpure I, Matisons R, Laivinš $M$, Gaitnieks T, Jansons J (2017). Natural regeneration of common ash in young stands in Latvia. Baltic Forestry 23 (1): 209-217. [online] URL: http:// www.balticforestry.mi.lt/bf/PDF_Articles/201723[1]/BalticForestry2017.1_209-217.pdf Queloz V (2016). Sterben ausgewachsene Eschen auch ab? [Do the adult ash trees die too?]. Wald und Holz 6: 23-26. [in German]

Rigling D, Hilfiker S, Schöbel C, Meier F, Engesser R, Scheidegger C, Stofer S, Senn-Irlet B, Queloz $V$ (2016). Le dépérissement des pousses du frêne. Biologie, symptômes et recommandations pour la gestion [The dieback of ash shoots. Biology, symptoms and management recommendations]. Notice pour le praticien 57 , WSL, Birmensdorf, Switzerland, pp. 8. [in French] [online] URL: http://www.wsl.ch/wsl/ dienstleistungen/publikationen/pdf/15794.pdf Salvadori C, Maresi G, Confalonieri M, Wolynski A (2013). Il monitoraggio fitosanitario delle fo- reste trentine: risultati e prospettive dopo oltre 20 anni di applicazione [Forest health monitoring in Trentino: results and perspectives after 20 years]. In: Proceedings of the "IX Congresso Nazionale SISEF - Multifunzionalità degli ecosistemi forestali montani: sfide e opportunità per la ricerca e lo sviluppo". Bolzano (Italy), 16-19 Sept 2013, pp. 80. [in Italian] [online] URL: http://hdl.handle.net/10449/23583

Schumacher J, Kehr R, Leonhard S (2010). Mycological and histological investigations of Fraxinus excelsior nursery saplings naturally infected by Chalara fraxinea. Forest Pathology 40: 419-429. - doi: 10.1111/j.1439-0329.2009.006 $15 . x$

Sitzia T (2009). Ecologia e gestione dei boschi di neoformazione nel paesaggio del Trentino [Ecology and management of neo formation wood in Trentino landscape]. Servizio Foreste e Fauna, Provincia di Trento, Trento, Italy, pp. 301. [in Italian]

Skovsgaard JP, Wilhelm GJ, Thomsen IM, Metzler B, Kirisits T, Havrdová L, Enderle R, Dobrowolska D, Cleary M, Clark J (2017). Silvicultural strategies for Fraxinus excelsior in response to dieback caused by Hymenoscyphus fraxineus. Forestry 90 (4): 455-472. - doi: 10.109 3/forestry/cpx012
Stanosz GR, Blodgett JT, Smith DR, Kruger EL (2001). Water stress and Sphaeropsis sapinea as a latent pathogen of red pine seedlings. New Phytologist 149: 531-538. - doi: 10.1046/j.14698137.2001.00052.x

Tulik M, Zakrzewski J, Adamczyk J, Tereba A, Yaman B, Nowakowska JA (2017). Anatomical and genetic aspects of ash dieback: a look at the wood structure. iForest 10: 522-528. - doi: 10.3832/ifor2080-010

Wolynski A (2005). I frassineti: un'occasione da non perdere [Ash stands: an occasion not to be lost]. Terra Trentina 51 (7): 37-39. [in Italian]

\section{Supplementary Material}

Fig. S1 - Apothecia of H. fraxineus on leaf debris of $F$. excelsior of the previous year.

Fig. S2 - Symptoms observed on natural regeneration of $F$. excelsior.

Fig. S3 - Different levels of damage, from healthy to severely affected, observed on F. excelsior trees in Primiero.

Link: Giongo_2486@supploo1.pdf 